\title{
FMF-15
}

2009 JSME-IIP/ASME-ISPS Joint Conference on Micromechatronics for Information and Precision Equipment (MIPE 2009)

June 17-20, 2009, Tsukuba International Congress Center, Ibaraki, Japan

\section{WEB WINDING SIMULATION AND WOUND ROLL STRESSES}

\author{
Shigeo YANABE ${ }^{*}$, Kengo TAKAHASHI ${ }^{*}$ and Toru YAMASHITA \\ * Department of Mechanical Engineering , Faculty of Engineering, Nagaoka University of Technology \\ 1603-1 Kamitomiokamachi, Nagaoka-city, Niigata-prefecture, 940-2188, JAPAN \\ E-mail:yanabe@mech.nagaokaut.ac.jp
}

\begin{abstract}
A new method for simulating web winding process and predicting wound roll stresses is proposed. The simulation model is two dimensional and is composed of a rigid core roll and a web. The simulation was carried out on a FEM software Marc to investigate effects of a slip between web layers and anisotropic web elasticity on the in-roll stresses. The results show that both the radial and circumferential stresses of the wound roll become conspicuously larger when the web layer slip is considered. The stresses for no slip case are similar to the results calculated by Hakiel model.
\end{abstract}

\section{INTRODUCTION}

Webs, such as films or papers, are generally wound in a roll form under certain winding conditions at the final stage of manufacturing. The winding conditions have serious effects on in-roll stress distributions and wound roll quality. In some cases, roll defects, such as star defect or telescope shift, appear in wound rolls. The roll stress distributions in the radial and circumferential directions have been calculated by the methods proposed by Aitman or Hakiel, and they are compared with experimental results. In the Hakiel model, the roll is assumed to be a collection of concentric hoops of web and winding is modeled as adding tensioned hoops onto the roll, neglecting slip between hoops. The roll has anisotropic non-linear properties and the roll stress distributions are a function of roll radius.

One of the authors has simulated a development of a folded wrinkle of a web transferred by a tilt roller with the aid of FEM software.

In the present study, firstly, a method for simulating web winding process is constructed by applying the FEM motion simulation. Secondly, the roll stress distributions and the slip between web layers are investigated.

\section{SIMULATION MODEL AND PROCEDURE}

Figure 1 shows a simulation model treated here. The model is two dimensional one and is composed of a rigid core roller with $20 \mathrm{~mm}$ in radius $\left(r_{c}\right)$ and a homogeneous web with $6 \mathrm{~m}$ in length, $1 \mathrm{~m}$ in width and $0.5 \mathrm{~mm}$ in thickness (h). The web is divided by quadrilateral plane strain elements with $2 \mathrm{~mm}$ in length and $0.25 \mathrm{~mm}$ in thickness. Young's modulus of the web is $50 \mathrm{Mpa}$ (for isotropic elasticity), Poisson's ratio is 0.01 and the winding tension is $240 \mathrm{~N}\left(=\mathrm{T}_{\mathrm{w}}\right)$ (see Table 1 ).

The simulation procedure is as follows. The web is moved to the core roller and the leading edge of the web is fixed to a node on the roller surface. After this, a tension is applied to the end edge of the web and the core roll is rotated at a constant angular velocity. The web is wound around the roll as the roll rotates by a constant angle at each calculation step $(0.01 \mathrm{rad} / \mathrm{step})$. The stress, slip, friction force and other quantities are calculated at each step and a motion simulation is obtained as a series of the calculated result of each step. The friction force acting between web layers is assumed here as a function of a friction coefficient $(\mu=0.1)$, normal force and slip velocity when it is considered. In this study, three cases are simulated considering both web anisotropic elasticity $(\mathrm{Er}=5 \mathrm{MPa})$ and $\mathrm{slip}$ between web layers as shown in Table 2.

\section{SIMULATION RESULTS}

Figure 2 shows a state of the wound roll in the FEM motion simulation when 80 web layers are wound. The in-roll stresses in the radial and the circumferential direction are obtained from the simulation results of $\sigma_{22}$ $\left(=\sigma_{r}\right)$ and $\sigma_{11}\left(=\sigma_{\theta}\right)$ at each nodal point. Assuming a reference radial line in Fig. 2 and collecting $\sigma_{i i}(i=1,2)$ values of the nodes ( $r$ is known) near the line, a distribution of each stress is obtained by plotting $\sigma_{\text {ii }}$ against $r$.

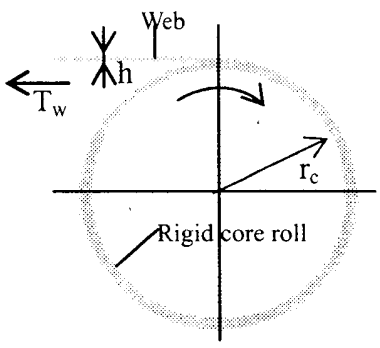

Fig. 1 Two dimensional FEM model for web winding

Table 1 Parameter values used in simulation

\begin{tabular}{|l|c|c|c|c|}
\hline $\mathrm{h}[\mathrm{m}]$ & $\mathrm{r}_{5}[\mathrm{~m}]$ & $\mathrm{Ec}[\mathrm{GPa}]$ & $\mathrm{Er}[\mathrm{MPa}]$ & $\mathrm{E}_{\theta}[\mathrm{MPa}]$ \\
\hline 0.0005 & 0.06 & 200 & $50 / 5$ & 50 \\
\hline
\end{tabular}




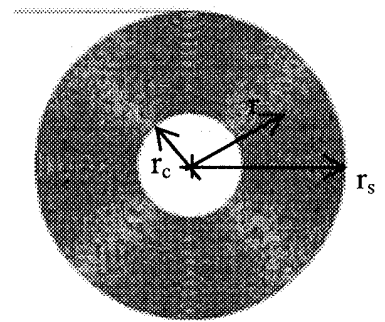

Fig. 2 Wound roll

(Simulation result at $80^{\text {th }}$ lap of winding)

Table 2 Simulation cases

\begin{tabular}{|c|c|c|}
\hline Case & Web elasticity & Slip between layers \\
\hline A & isotropic & no slip \\
\hline B & anisotropic & no slip \\
\hline C & isotropic & $\operatorname{slip~}(\mu=0.1)$ \\
\hline
\end{tabular}

Figure 3(a) and (b) show the comparison of the in-roll stress distributions among the three simulation cases together with the calculated results of Hakiel model. These figures indicate the followings. (1) The simulation results of $\sigma_{r}$ and $\sigma_{\theta}$ in Case $\mathrm{C}$ (slip case) are conspicuously larger than those of other cases, and in the web inner region $\sigma_{\theta}$ fluctuates largely. These seem to be the effects of the web layer slip. (2) The simulated results of $\sigma_{r}$ and $\sigma_{\theta}$ in Cases of A and B (no-slip cases) are in relatively good agreement with the results calculated by Hakiel model. Especially, in Case B, $\sigma_{\theta}$ becomes negative in the vicinity of $\mathrm{r} / \mathrm{rc}=1.5$, that means, $\sigma_{\theta}$ is compression.

Figure 4(a) and (b) show the slip between layers during winding. At the $5^{\text {th }}$ lap of the winding (Fig.4(a)), reference nodal points $\mathrm{A} \sim \mathrm{E}$ lie closely on a radial line, but at $80^{\text {th }}$ lap, they are situated apart from each other in the circumferential direction (Fig.4(b)). The web layers slip largely in the inner region of the roll and the slip occurs irregularly at each position. This can be the reason for the above (1).

\section{CONCLUSIONS}

The following conclusions are obtained.

(1) A web winding simulation is constructed by the help of a FEM software. The simulation of 80-lap winding takes about 100 hours.

(2) The simulated in-roll stress distributions are in relatively good agreement with the results calculated by Hakiel model for the cases of neglecting the slip between web layers.

(3) The slip occurs largely in the inner region of the wound roll and it makes the in-roll stresses very large comparing with the cases of (2).

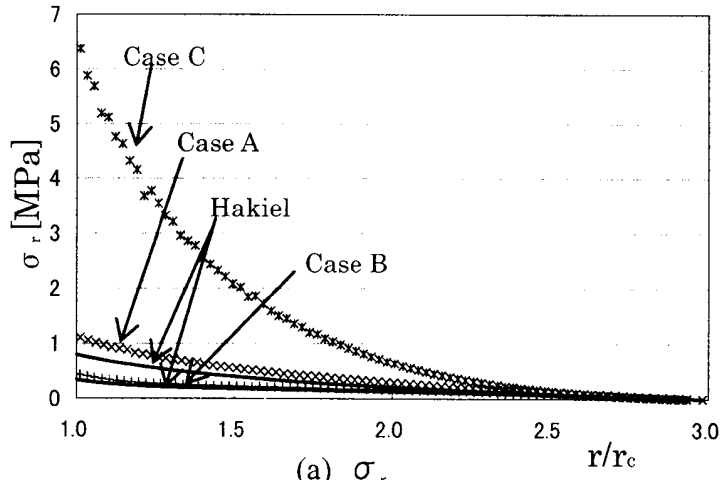

(a) $\sigma_{\mathrm{r}}$

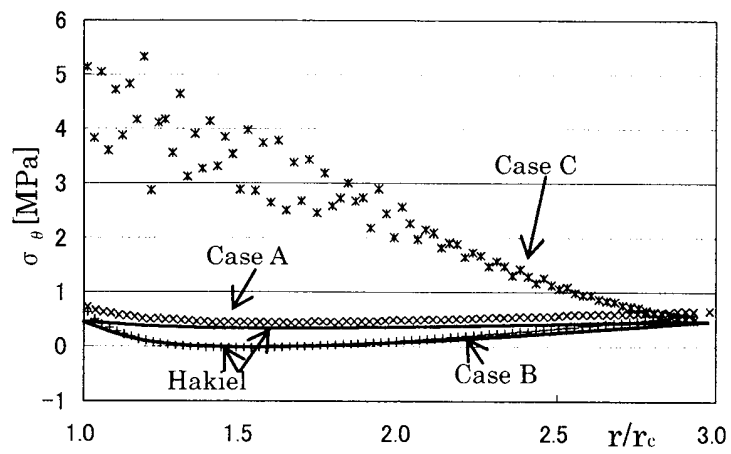

(b) $\sigma_{\theta}$

Fig. 3 In-roll stress distributions (Effects of web layer slip and anisotropic web elasticity)

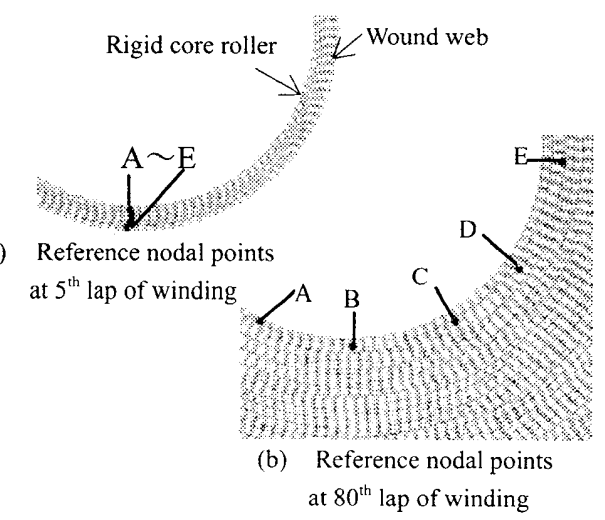

Fig. 4 Slip between web layers during winding ( Case C)

\section{REFERENCES}

[1] Altman, H. C., Formulaa for Computing the Stresses in Center-Wound Rolls, Tappi Journal, Vol. 51, No.4, 1968, pp. 176-1793.

[2] Hkiel, Z., Nonlinear model for wound roll stresses, Tappi Journal, Vol. 70, 1987, pp. 113-117.

[3] Lee, Y. M., and Wickert, J.A., Stress Field in Finite Width Axisymmetric Wound Rolls, Trans.ASME, J. Appl. Mech., Vol. 69, 2002, pp. 130-138. 